\title{
Erratum to: Warming Effect on Miriplatin-Lipiodol Suspension as a Chemotherapeutic Agent for Transarterial Chemoembolization for Hepatocellular Carcinoma: Preliminary Clinical Experience
}

\author{
Shinn-ichi Kora $\cdot$ Hiroshi Urakawa $\cdot$ \\ Toshimichi Mitsufuji • Akinobu Osame • \\ Hideyuki Higashihara $\cdot$ Kengo Yoshimitsu
}

Published online: 21 August 2013

(C) Springer Science+Business Media New York and the Cardiovascular and Interventional Radiological Society of Europe (CIRSE) 2013

Erratum to: Cardiovasc Intervent Radiol

(2013) 36:1023-1029

DOI 10.1007/s00270-012-0537-3

The authors regret that there were several errors in the published article, details of which are shown below.

1. P 1024, right column, 4th line from the bottom: "currently approved in Japan is $7 \mathrm{~mL}$ " should be changed to "currently approved in Japan is $\mathbf{6} \mathrm{mL}$ ".

2. P 1026, Table 1, Sex (M:F) of W group, "14:6" should be changed to "13:5".
3. P 1026, Table 1, the numbers of patients for ChildPugh grades A and B in W group, "11 and 9" should be changed to " 10 and 8 ", respectively.

4. P 1027, Table 2, $\mathrm{W}$ group (40 nodules in 26 patients) should be changed to "W group (51 nodules in 25 patients)".

5. P 1029, left column, Acknowledgements: The name "Toshiro Ohki" should be changed to "Toshihiro Ohki".

The online version of the original article can be found under doi:10.1007/s00270-012-0537-3.

S. Kora $\cdot$ H. Urakawa $\cdot$ T. Mitsufuji $\cdot$ A. Osame

K. Yoshimitsu ( $\square$ )

Department of Radiology, Faculty of Medicine, Fukuoka

University, 7-45-1, Nanakuma, Jonan-ku, Fukuoka 814-0180,

Japan

e-mail: kengo@fukuoka-u.ac.jp

H. Higashihara

Department of Radiology, Fukuoka University Chikushi

Hospital, 1-1-1, Zokumyouin, Chikushino-shi, Fukuoka 818-

1011, Japan 